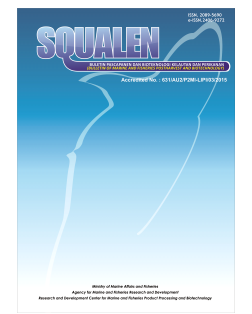

Squalen Bull. of Mar. and Fish. Postharvest and Biotech. 11 (1) 2016, 7-12

www.bbp4b.litbang.kkp.go.id/squalen-bulletin

Squalen Bulletin of Marine and Fisheries Postharvest and Biotechnology

ISSN: $2089-5690$

e-ISSN: 2406-9272

\title{
ETHANOLIC FERMENTATION EFFICIENCY OF SEAWEED SOLID WASTE HYDROLYSATES BY Saccharomyces cerevisiae
}

\author{
Pujoyuwono Martosuyono ${ }^{*}$, Ifah Munifah ${ }^{1}$ and Gesty Aulia Ningrum ${ }^{2}$ \\ ${ }^{1}$ Research and Development Center for Marine and Fisheries Product Competitiveness and Biotechnology, \\ Jalan KS. Tubun Petamburan VI, Slipi, Central Jakarta 10260, Indonesia \\ ${ }^{2}$ Department of Biology, Faculty of Science and Technology, Syarif Hidayatullah Islamic State University, Indonesia, \\ Jalan Ir. H.Djuanda No. 95 Ciputat Tangerang Selatan, Banten 15412, Indonesia \\ Article history: \\ Received: 4 January 2016; Revised: 18 April 2016; Accepted: 29 April 2016
}

\begin{abstract}
The objective of this research was to determine the saccharification and the fermentation efficiency of seaweed solid waste hydrolysate by Saccharomyces cerevisiae (Accession number 3012.254) in anaerobic condition. The optimum saccharification yield of acid pretreated waste $(40.93 \pm 1.72) \%$ was obtained after 48 hours with saccharification rate of $(0.51 \pm 0.02) \mathrm{g} / \mathrm{l}$.h. Higher yield was shown by $\mathrm{NaOH}$ pretreated waste $(67.29 \pm 1.24) \%$ after 24 hours with saccharification rate of $(0.81 \pm 0.06) \mathrm{g} / \mathrm{l}$.h. The fermentation of enzymatic hydrolysates of acid and alkali pretreated samples by $S$. cerevisiae produced a maximum of $7.52 \pm 0.24 \mathrm{~g} / \mathrm{l}$ and $14.5 \pm 0.54 \mathrm{~g} / \mathrm{l}$ ethanol respectively after 72 hours fermentation. Maximum ethanol yield was $0.31 \pm 0.03 \mathrm{~g} / \mathrm{g}$ and $0.40 \pm 0.02 \mathrm{~g} / \mathrm{g}$ sugar respectively for acid and alkali pretreated samples. The ethanol yields showed that alkali pretreated sample produces higher conversion substrate ratio ( $80 \%$ of theoretical yield) compared to acid pretreated sample (62\% of theoretical yield).
\end{abstract}

Keywords: bioethanol, Saccharomyces cerevisiae, solid seaweed waste

\section{Introduction}

Common bioethanol feedstocks, such as sugarcane, maize, and wheat, which are all land-based crops, have been studied extensively (Lee, 1997). However, little work has been conducted on marine sources of biomass, such as macroalgae and its wastes. In fact, almost $50 \%$ of global biomass is produced in marine environment (Carlsson et al., 2007), which shows that marine biomass has great potential as feedstock for future bioethanol production. In addition, the issues of extensive land use for biomass crops and the debate on "food versus fuels" are not applicable for macroalgae. Another important fact is that polysaccharide fibers from macroalgae have different characteristics from terrestrial plant because there is almost no lignin (Yanagisawa et al., 2011) and it is built from specific monosaccharides, such as galactose, glucoronic acid, alginic acid, fucose, xylose, and mannitol, which can be converted to bioethanol through fermentation process (Borines et al., 2011).
The world annual production of marine algae is approximately 14 million tons, and is predicted to rise to more than 22 million tons in 2020 (Kim et al., 2011). The growth rate of algae in the environment is very high, but the biomass accumulation is low because macroalga lifespan is short and can be quickly degraded and naturally recycled (Borines et al., 2011). The utilization of algae biomass as a source of biofuel feedstock plays an extremely important role as the requirement of macroalgae production is very simple, which consists of sea water, sunlight, and carbon dioxide.

Research on the utilization of marine alga biomass as bioethanol feedstock gains considerably more attention, so intense research is required for efficient utilization of this biomass. Currently, the use of macroalgae and its wastes to produce fuel ethanol still faces significant technical and economic challenges. The success of macroalga bioconversion into biofuel depends on the development of 'green' pretreatment methods, highly effective enzyme

${ }^{*}$ Corresponding author.

E-mail: pujo_yuwono@yahoo.com.au 
systems, and efficient microorganisms to convert fermentable sugars into ethanol.

The fermentation process of hydrolysates is a crucial stage as the monosaccharides produced from the saccharification process of seaweed waste consist of glucose and other monosaccharides, which are not the normal substrate for Saccharomyces cerevisiae, an ethanol that produces yeast (Setyaningsih et al., 2012). Previous research on the optimization of pretreatment and saccharification produces high content of reduced sugar, which is comparable to other techniques of those on raw seaweed sugar as the substrate (Martosuyono et al., 2015). However, the bioconversion efficiency of fermentable sugar produced by acid/alkali pretreatment by $S$. cerevisiae fermentation into ethanol needs more research. The objective of this research was to determine the saccharification and fermentation efficiency of seaweed solid waste hydrolysate by S. cerevisiae in anaerobic condition.

\section{Material and Methods}

\subsection{Raw Materials}

The seaweed solid waste was taken from smallscale agar processing unit in Pameungpeuk, District of Garut, West Java. The material was sun dried and grounded to size 20-80 meshes prior to the pretreatment and prior to its use as fermentation substrate. Saccharomyces cerevisiae yeast was obtained from Gadjah Mada University (UGM) Culture Collection (Accession number 3012.254), which was maintained on PDA medium at $4{ }^{\circ} \mathrm{C}$ prior to fermentation.

\subsection{Dilute Acid and Alkali Pretreatment}

The dilute acid and the alkali pretreatment of solid seaweed waste were carried out at $121{ }^{\circ} \mathrm{C}$ for $1 \%$ sulfuric acid (w/v) and $4 \% \mathrm{NaOH}(\mathrm{w} / \mathrm{v})$ for 30 minutes. The ratio of waste: acid/alkali was 1:5 (1 $\mathrm{g}$ of sample added by $5 \mathrm{ml}$ of acid/alkali). The insoluble residue was separated through filtration and was washed thoroughly with hot water. The solid residue was dried in the oven and was milled for enzymatic saccharification experiment.

\subsection{Enzymatic Saccharification}

A crude cellulase enzyme was used in this experiment for the saccharification procedure. The enzyme was purchased from Pulp and Paper Research Center, Ministry of Industrial Affairs in Bandung. The saccharification process was conducted at $50 \mathrm{U} / \mathrm{g}$ substrate concentration at $50^{\circ} \mathrm{C}$ for 48 hours. The concentration of sugar reduction was analyzed at $0,6,12,18,24,36$ and 48 hour. Sugar concentration was measured by reacting the saccharification product with 3,5-dinitrosalycilic acid (DNS) and read at $575 \mathrm{~nm}$ absorbance. The rate of saccharification process and the yield of saccharification were calculated as follows (Kumar et al., 2013; Tan \& Lee, 2014):

$\begin{aligned} & \text { Saccharification } \\ & \text { rate }(\mathrm{g} / \mathrm{L} . \mathrm{h})\end{aligned}=\frac{\begin{array}{l}\text { Amount of sugar } \\ \text { at certain point }\end{array}}{\begin{array}{l}\text { Time }(\mathrm{h}) \\ \text { Saccharification } \\ \text { yield }(\%)\end{array}}=\frac{\begin{array}{l}\text { Amount of sugar } \\ \text { during hydrolysis }\end{array}}{\begin{array}{l}\text { Amount of } \\ \text { holocellulose in initial } \\ \text { substrate } \times 1.1\end{array}}$

\subsection{Fermentation}

The stock cultures of $S$. cerevisiae was maintained in YMGP media with the composition of $5 \mathrm{~g} / \mathrm{l}$ yeast extract, $5 \mathrm{~g} / \mathrm{l}$ maltose, $40 \mathrm{~g} / \mathrm{l}$ glucose, and $5 \mathrm{~g} / \mathrm{l}$ peptone, incubated at room temperature for $24-48$ hours as a starter. The starter was then inoculated in a media containing seaweed solid waste hydrolysate enriched with $10 \mathrm{~g} / \mathrm{l}$ yeast extract, $1.0 \mathrm{~g} / \mathrm{l}\left(\mathrm{NH}_{4}\right)_{2} \mathrm{SO}_{4}, 1.0 \mathrm{~g} / \mathrm{l}$

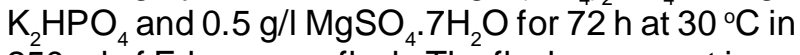
$250 \mathrm{ml}$ of Erlenmeyer flask. The flasks were put in an anaerobic jar with oxoid anaerobic generation kit. Fermentation was carried out in shaker incubator with set temperature at $30^{\circ} \mathrm{C}$ and $150 \mathrm{rpm}$. The ethanol concentration and sugar residue were analyzed at 2 , $4,8,12,24,36,48$, and 72 hours. The efficiency of substrate utilization and the yield of ethanol production were calculated. As an index to evaluate the conversion efficiency from sugar to ethanol in the fermentation, the overall ethanol yield was defined as follows (Kumar et al., 2013; Tan \& Lee, 2014):

$$
\begin{aligned}
& \begin{array}{l}
\text { Sugar uptake } \\
\text { ratio }(\%)
\end{array}=\frac{\begin{array}{l}
\text { Amount of sugar } \\
\text { consumption at certain time }
\end{array}}{\text { Initial sugar concentration }} \times 100 \\
& \begin{array}{l}
\text { Concentration of ethanol } \\
\text { produced }
\end{array}
\end{aligned}
$$

where, 0.51 indicates the theoretical ethanol yield ( $0.51 \mathrm{~g}$-ethanol/g-sugar). Moreover, to evaluate sugar consumption and conversion efficiency, we used sugar uptake ratio and ethanol yield. The sugar uptake ratio was defined as the percentage of the amount of sugar consumed during fermentation divided by the amount of sugar at the start of the fermentation. Ethanol yield was defined as the amount of ethanol produced divided by the amount of sugar consumed during fermentation. 


\section{Results and Discussion}

The holocellulose (cellulose plus hemicellulose) content of the sample was found to be approximately $35 \%$. The ratio of hemicellulose and cellulose is very low. As the hemicelluloses content of the sample was extremely lower than alpha-cellulose, this suggests that mild pretreatment of the sample prior to bioethanol production is needed. Through pretreatment, hemicellulose components may be solubilized to monomeric sugars, such as xylose, arabinose, and galactose, making the cellulose more accessible for enzymatic breakdown.

The content of seaweed solid waste cellulose after pre-treatment using $\mathrm{H}_{2} \mathrm{SO}_{4}$ increased to $33 \%$ and $44 \%$ from the initial concentration of $20 \%$. However, through $\mathrm{NaOH}$ treatment, the cellulose content increased to more than $80 \%$. It means that alkali pre-treatment effectively removes any unwanted contents other than cellulose. As shown by statistical analysis (ANOVA), the cellulose content of waste pretreated by $\mathrm{NaOH}$ was significantly different than those pretreated by sulfuric acid at $95 \%$ confident level.

\subsection{Enzymatic Saccharification}

The profiles of enzymatic saccharification of acid and alkali pretreated seaweed solid waste are shown in Figure 2 and 3. The time course of enzymatic saccharification of seaweed solid waste exhibited a regular increase in sugar release, both in acid and alkali pretreated waste. The maximum sugar concentration of acid pretreated waste was $(25.08 \pm 0.72) \mathrm{g} / \mathrm{L}$ sugar at 36 hours and $(41.23 \pm 0.84)$ $\mathrm{g} / \mathrm{L}$ sugar for $\mathrm{NaOH}$ pretreated waste at 24 hours, which remained almost constant thereafter (Figure 1 and 2). The maximum rate of acid and alkali pretreated seaweed waste saccharification was $(0.72 \pm 0.06) \mathrm{g} /$ L.h at 24 hours for acid pretreatment and $(2.61 \pm 0.09)$ $\mathrm{g} / \mathrm{L} . \mathrm{h}$ at 12 hours for $\mathrm{NaOH}$ pretreatment. The saccharification rate for both pretreatments declined gradually after 24 hours for acid pretreatment and 12

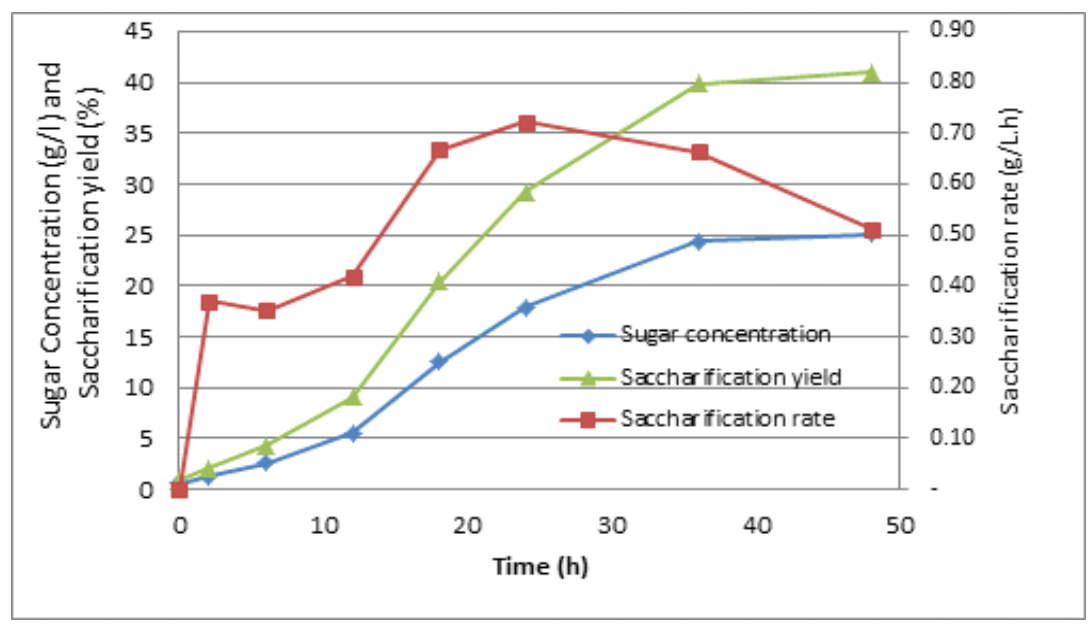

Figure 1. Enzymatic hydrolysis of $1 \% \mathrm{H}_{2} \mathrm{SO}_{4}$ pretreated seaweed solid waste.

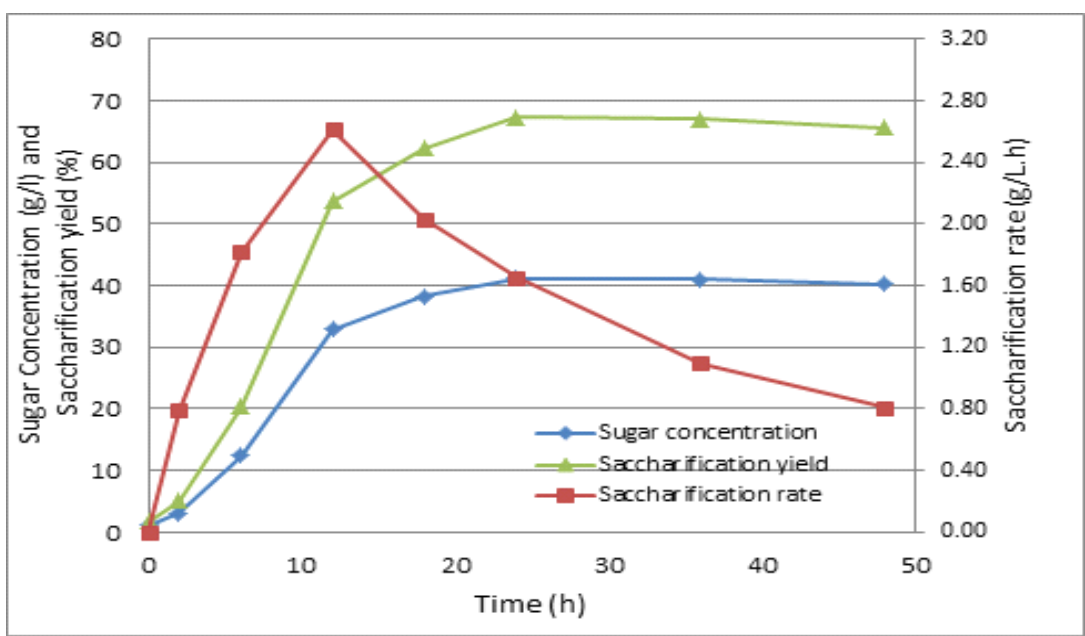

Figure 2. Enzymatic hydrolysis of $4 \% \mathrm{NaOH}$ pretreated seaweed solid waste. 
Table 1. Comparison of saccharification parameters of acid and alkali pretreated solid seaweed waste

\begin{tabular}{lcc}
\hline \multicolumn{1}{c}{ Parameters } & Acid Pretreated & Alkali Pretreated \\
\hline Sugar concentration $(\mathrm{g} / \mathrm{l})$ & 25.48 & 40.25 \\
Saccharification yield $(\mathrm{g} / \mathrm{g})$ & 40.93 & 65.69 \\
Saccharification rate $(\mathrm{g} / \mathrm{l} . \mathrm{h})$ & 0.51 & 0.81 \\
\hline
\end{tabular}

hours for $\mathrm{NaOH}$. It shows reciprocal relationship with saccharification efficiency, which is similar to earlier reports on raw seaweed samples (Gupta et al., 2009; Kuhad et al., 2010). Regular decrease in the hydrolysis rate may be attributed to the end product inhibition of the enzymes by glucose and cellobiose (Kuhad et al., 1999).

Optimum saccharification yield of acid pretreated waste $(40.93 \pm 1.72) \%$ was obtained after 48 hours with a saccharification rate of $(0.51 \pm 0.02) \mathrm{g} / \mathrm{L}$.h. Higher yield was shown by $\mathrm{NaOH}$ pretreated waste $(67.29 \pm 1.24) \%$ at 24 hours with saccharification rate of $(0.81 \pm 0.06) \mathrm{g} / \mathrm{L}$.h. Moreover, the saccharification efficiency obtained in this study (68\%) was higher than the saccharification efficiency of seaweeds raw material, such as Ulva pertusa, Alaria crassifolia and Gelidium elegans (Yanagisawa et al., 2011), and Kappaphycus alvarezii (Khambhaty et al., 2012).

Diluted sulfuric acid was mixed with biomass to hydrolyze hemicellulose, to xylose, and other sugars, and then continued to break the xylose down to form furfural, which is known as toxic chemicals for enzymatic saccharification. Alkali pretreatment technologies, including lime pretreatment, are rather similar to the Kraft paper pulping technology. The major effect of alkaline pretreatment is the removal of lignin from the biomass, which improves the reactivity of the remaining polysaccharides. In addition, alkali pretreatments remove acetyl and various uronic acid substitutions on hemicellulose that lower the accessibility of the enzyme to hemicellulose and cellulose surface (Chang \& Holtzapple, 2000). These facts explain why alkali pretreatment gives better results in sugar concentration during saccharification as well as the ethanol concentration, ethanol yield, and ethanol productivity of alkali pretreated samples followed by enzymatic saccharification are higher than those of acid pretreated samples. Saccharification parameters (sugar concentration, saccharification yield, and saccharification rate) were shown in Table 1.

\subsection{Fermentation Studies}

Figure 3 and 4 shows changes in sugar and ethanol concentrations in seaweed hydrolysates for 72 hours of fermentation. The fermentation of enzymatic hydrolysates of acid and alkali pretreated samples with $S$. cerevisiae produced maximum ethanol
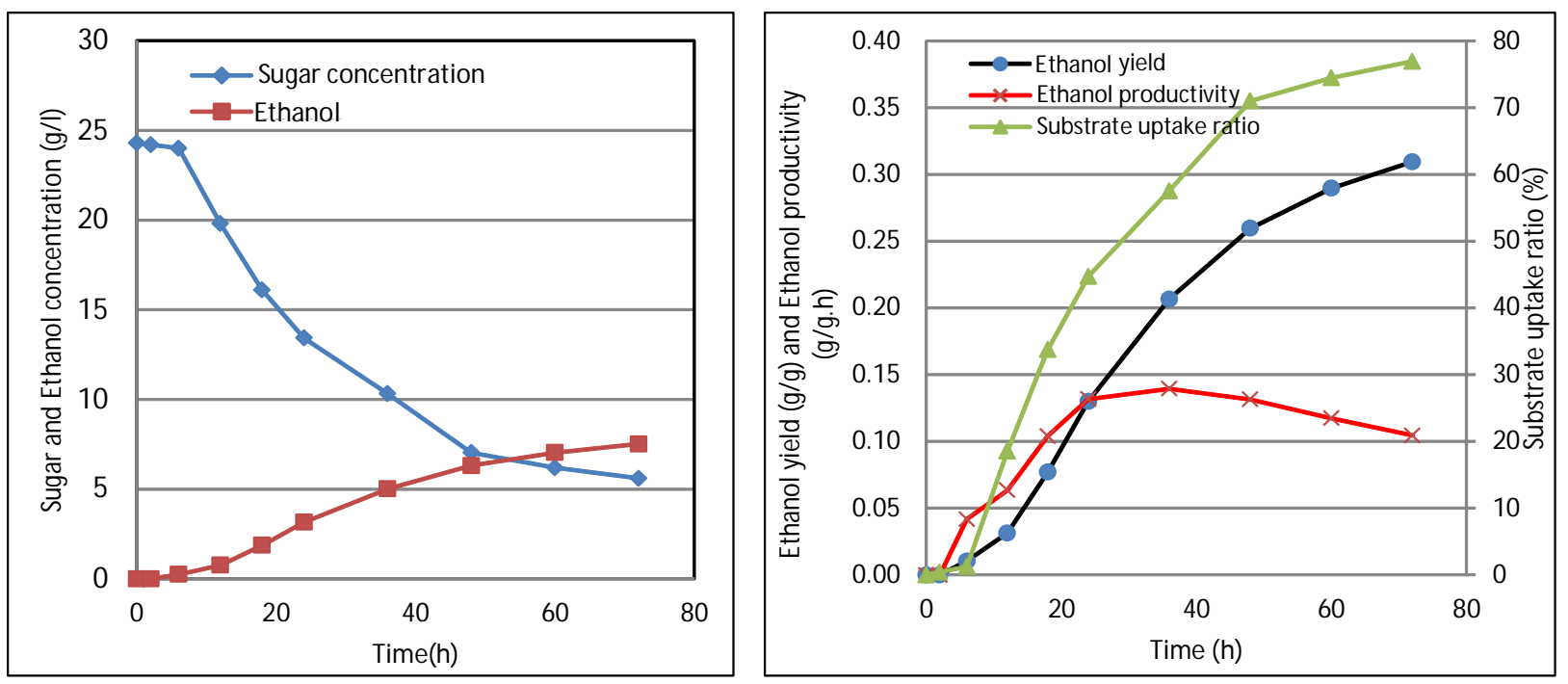

Figure 3. Fermentation profile of enzymatic hydrolysate of solid seaweed waste pretreated by $1 \% \mathrm{H}_{2} \mathrm{SO}_{4}$. 

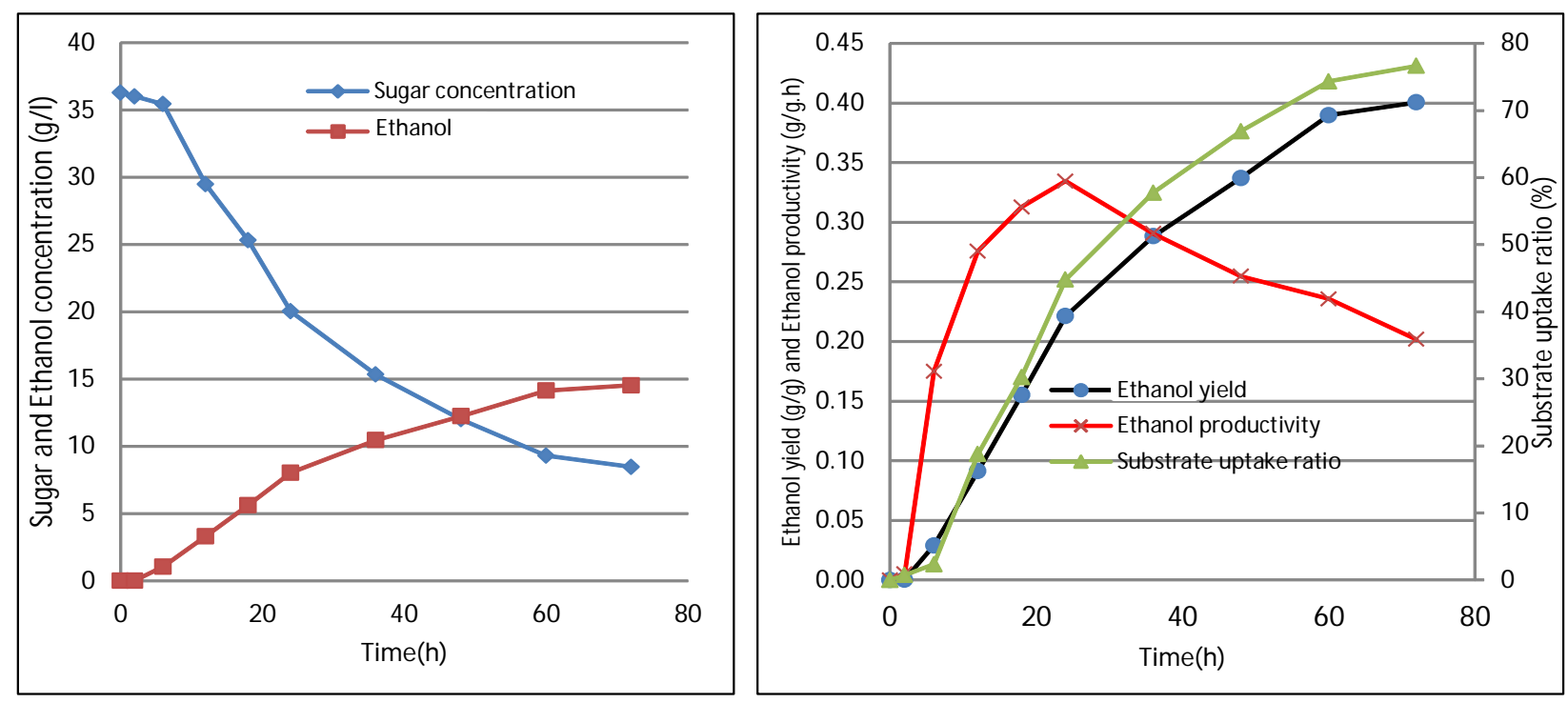

Figure 4. Fermentation profile of enzymatic hydrolysate of solid seaweed waste pretreated by $4 \% \mathrm{NaOH}$.

Table 2. Comparison of fermentation parameters of acid and basic pretreated solid seaweed waste

\begin{tabular}{lcc}
\hline \multicolumn{1}{c}{ Parameters } & Acid Pretreated & Alkali Pretreated \\
\hline max ethanol concentration $(\mathrm{g} / \mathrm{l})$ & 7.52 & 14.53 \\
max ethanol yield $(\mathrm{g} / \mathrm{g})$ & 0.31 & 0.4 \\
\% of theoretical yield & $62 \%$ & $80 \%$ \\
max ethanol productivity (g/g.h) & 0.14 & 0.33 \\
substrate uptake ratio (\%) & 77.0 & 76.7 \\
\hline
\end{tabular}

$(7.52 \pm 0.24) \mathrm{g} / \mathrm{l}$ and $(14.5 \pm 0.54) \mathrm{g} / \mathrm{l}$ respectively after 72 hours fermentation. Maximum ethanol yield $(0.31 \pm 0.03) \mathrm{g} / \mathrm{g}$ and $(0.40 \pm 0.02) \mathrm{g} / \mathrm{g}$ sugar respectively for acid and alkali pretreated samples. The ethanol yields show that alkali pretreated sample produced higher conversion ratio of substrate $(80 \%$ of theoretical yield) compared to acid pretreated sample $(62 \%$ of theoretical yield), which was found to be comparatively better than earlier reports on using algal biomass for bioethanol production (Hyeon et al., 2011; Yanagisawa et al., 2011 ). Hyeon and coworkers obtained an ethanol yield of $0.386(\mathrm{~g} / \mathrm{g})$ using Sargassum sagamianum biomass, while Yanagisawa et al. (2011) who used $U$. pertusa, A. crassifolia, and G. elegans biomass for ethanol production reported an ethanol yield of $0.381,0.281$ and $0.376 \mathrm{~g} / \mathrm{g}$, respectively. Interestingly, the ethanol yield from seaweed waste used in this experiment was also found comparable with the previously reported ethanol yields from various lignocellulosics materials, such as corncob $(0.48 \mathrm{~g} / \mathrm{g}$ sugars; 96\% theoretical yield) (Chen et al., 2007 )
Prosopis juliflora $(0.49 \mathrm{~g} / \mathrm{g}$ sugars; $98 \%$ theoretical yield) (Gupta et al., 2009), Lantana camara $(0.48 \mathrm{~g} / \mathrm{g}$ sugars; 96\% theoretical yield) (Kuhad et al., 2010), and newspaper waste $(0.39 \mathrm{~g} / \mathrm{g}$ sugars; $78 \%$ theoretical yield) (Kuhad et al., 2010).

The yeast used here produced maximum ethanol from enzymatic hydrolysate of seaweed solid waste hydrolysates after 60 hours of fermentation and it declined thereafter (Figure 3 and 4). The decline in ethanol production after 60 hours of fermentation could be attributed to the consumption of accumulated ethanol by the organism as had been observed in the earlier studies (Gupta et al., 2009; Kuhad et al., 2010). According to Ramon-portugal et al. (2004), when ethanol is accumulated in the medium, the microbial population adapts to consume sugar and ethanol simultaneously.

The comparison of some fermentation parameters by $S$. cerevisiae on acid and alkali pretreated samples prior to enzymatic saccharification is shown in Table 2. 
All parameters, except substrate uptake ratio, showed higher basic pretreatment compared to acid pretreatment.

\section{Conclusion}

Enzymatic saccharification performance by cellulase enzyme on alkali pretreated samples is better than those on acid pretreated samples. Sugar concentration, saccharification yield, and saccharification rate show higher values. Maximum sugar concentration and saccharification yield significantly are improved by $\mathrm{NaOH}$ pretreated samples compared to acid pretreatment. The maximum saccharification rate on $\mathrm{NaOH}$ pretreatment samples was reached at shorter time (10 hours) than acid pretreatment ( 24 hours) and maximum yield at 24 and 36 hours respectively. The fermentation parameters of $\mathrm{NaOH}$ pretreated samples showed better results than $\mathrm{H}_{2} \mathrm{SO}_{4}$. The maximum ethanol concentration, ethanol yield, and ethanol productivity are significantly higher on alkali pretreatment than acid pretreatment. The comparable results were only shown by substrate uptake ratio on both pretreatments.

\section{References}

Borines, M. G., de Leon, R. L., \& McHenry, M. P. (2011) Bioethanol production from farming nonfood macroalgae in Pacific island nations: Chemical constituents, bioethanol yields, and prospective species in the Philippines. Renew. Sustain. Energy Rev., 15, 123-128.

Carlsson A, van Beilen J, Moller R, \& Clayton D. (2007). Micro- and macro-algae: utility for industrial applications. In: Bowles D (ed) Outputs from the EPOBIO project. CNAP, University of York, York, UK.

Chang, V.S., \& Holtzapple, M.T. (2000). Fundamental factors affecting biomass enzymatic reactivity. Appl. Biochem. and Biotechnol. 84, 5-37.

Chen, M., Xia, L., \& Xue, P. (2007). Enzymatic hydrolysis of corncob and ethanol production from cellulosic hydrolysate. Int. Biodeterior. Biodegrad. 59, 85-89.

Gupta R, Sharma K.K, \& Kuhad, R.C. (2009). Separate hydrolysis and fermentation (SHF) of Prosopis juliflora, a woody substrate, for the production of cellulosic ethanol by Saccharomyces cerevisiae and Pichia stipitis-NCIM 3498. Bioresour Technol. 100(3), 1214-20.
Hyeon, Y.J., Lee, S.E., Choi, W.Y., Kang, D.H., Lee, H.Y., \& Jung, K.H. (2011). Repeated batch operation of surface-aerated fermentor for bioethanol production from the hydrolysate of seaweed Sargassum sagamianum. J. Microbiol. Biotechnol. 21, 323-331.

Khambhaty, Y., Mody, K., Gandhi, M.R., Thampy, S., Maiti, P., Brahmbhatt, H., Eswaran, K., \& Ghosh, E.K. (2012). Kappaphycus alvarezii as a source of bioethanol. Bioresour. Technol. 103, 180-185.

Kim, N. J., Li, H., Jung, K., Chang, H. N., \& Lee, P. C. (2011). Ethanol production from marine algal hydrolysates using Escherichia coli KO11. Bioresour. Technol., 102, 7466-7469.

Kuhad, R.C., Manchanda, M., \& Singh, A. (1999). Hydrolytic potential of extracellular enzymes from a mutant strain of Fusarium oxysporum. Bioprocess Eng. 20, 47-125.

Kuhad, R.C., G.. Mehta, R. Gupta, \& K. K. Sharma. (2010). "Fed batch enzymatic saccharification of newspaper cellulosics improves the sugar content in the hydrolysates and eventually the ethanol fermentation by Saccharomyces cerevisiae," Biomass and Bioenergy, 34(8), 1189-1194.

Kumar, S., R. Gupta, G. Kumar, D. Sahoo, R.C. Kuhad. (2013). Bioethanol production from Gracilaria verrucosa, a red alga, in a biorefinery approach. Bioresour Technol.135,150-156.

Lee, J. (1997). Biological conversion of lignocellulosic biomass to ethanol. J. of Biotechnology 56(1),1-24.

Martosuyono, P., A. Hakim., \& Y.N. Fawzia. (2015). Chemical Pretreatment and Enzymatic Saccharification of Solid Seaweed Wastes. Squalen, 10(2), 61-71.

Ramon-portugal, F., Pingaud, H., \& Strehaiano, P. (2004). Metabolic transition step from ethanol consumption to sugar/ethanol. Biotechnol. Lett. 26, 1671-1674.

Setyaningsih, D., S. Windarwati, I., Khayati, N., Muna., \& P. Hernowo. (2012). Acid Hydrolysis Technique and Yeast Adaptation to Increase Red Macroalgae Bioethanol Production. Int. J. of Environ. and Bioenergy, 3(2), 98-110.

Tan, I.S. \& Lee, K.T. (2014). Enzymatic hydrolysis and fermentation of seaweed solid. wastes for bioethanol production: an optimation study. Energy xxx: 1-10.

Yanagisawa, M., Kanami, N., Osamu, A., \& Kiyohiko, N. (2011). Production of high concentrations of bioethanol from seaweeds that contain easily hydrolyzable polysaccharides. Proc. Biochem., 46, 2111-2116. 